University of Nebraska - Lincoln

DigitalCommons@University of Nebraska - Lincoln

French Language and Literature Papers

Modern Languages and Literatures, Department

2021

Diamant brut

Marie Cosnay

Follow this and additional works at: https://digitalcommons.unl.edu/modlangfrench

Part of the French and Francophone Language and Literature Commons

This Article is brought to you for free and open access by the Modern Languages and Literatures, Department of at DigitalCommons@University of Nebraska - Lincoln. It has been accepted for inclusion in French Language and Literature Papers by an authorized administrator of DigitalCommons@University of Nebraska - Lincoln. 


\section{Marie Cosnay}

\section{Diamant brut}

Ce coup de fil, au petit matin. Le coup de fil porte les ingrédients d'une histoire. Au cœur de l'histoire racontée au téléphone, une enfant. D'Irun, Poitiers et Bruxelles, chacun dans sa chambre ou cuisine du petit déjeuner, nous sommes projetés, par ondes électromagnétiques, au cœur de l'histoire dans laquelle il y a, comme protagoniste principale, une enfant, 15 ans, venue de Conakry. D'Irun on nous dit, au téléphone : un ange, une perle, un diamant, on ajoute : brut. Un diamant brut.

Le diamant brut avait quitté son pays pour en remonter d'autres, territoires après territoires, territoires sans nom et sans spécificité sinon du point de vue des plus ou moins grands dangers qu'on y rencontrerait, ici le viol, ici le feu du soleil, là les policiers jetant des pierres, la noyade, les centres, puis le vide total parce qu'il n'y a plus de route. La route, c'est fini, Espagne France Belgique Allemagne et demi-tour. Europe est une terre avant une autre terre, mais il n'y a pas d'autre terre, Europe n'est qu'une étape avant un but mais il n'y a pas d'autre but. On est arrivé à la fin et on tourne dans la fin comme dans une cage.

Published in Lydie Salvayre, maintenant même, ed. Warren Motte (Lincoln, NE : Zea Books, 2021). doi: 10.32873/unl.dc.zea.1288 
L'enfant, 15 ans, le diamant brut, appelle au secours. Appelle Irun au secours parce qu'Irun a croisé sa route et Irun au petit matin appelle à son tour au secours. Le diamant brut ne sait pas dans quel pays elle est arrivée, y est arrivée avec deux adultes qui ont disparu voici trois jours. Le diamant brut, dite l'ange à Irun, est enfermée dans une pièce dont elle n'a pas la clef, si elle sort ne rentrera plus, les adultes parents ont disparu, le pays sans nom d'Europe les a mangés. Irun géolocalise l'enfant par téléphone portable, voici l'adresse, porte de Namur, Ixelles. La rue, de tel à tel numéro. Belgique donc. Irun dépêche des éclaireurs de Belgique contactés de Poitiers, les éclaireurs de Belgique crient, dans la rue, aux fenêtres, le prénom du diamant angélique. L'enfant fermée ou dedans ou dehors, pas de passage possible dans un pays qui n'a pas de nom et ne permet, puisqu'on est arrivé, lui non plus, aucun passage. Le piège, et la panique. D'Irun à Poitiers à Ixelles on se fait passer l'histoire à trous, on a très peu de choses pour ravauder les trous, on fait avec le très peu, on ajoute des éléments, des hypothèses, les éléments-hypothèses débordent l'histoire, par le bas, par le haut, c'est l'endroit fourmillant de la croissance des histoires et on est, Irun, Poitiers et Ixelles, heureux de la croissance fourmillante des histoires parce qu'on sait que jamais aucune histoire n'est une somme chronologique stricte de personnages, psychologies, d'accidents.

Tout ce monde, d'autres encore, autour d'une enfant passée à Irun, accompagnée de cousin cousine, tout ce monde, malgré les éléments chaotiques de l'histoire, autour d'une enfant qui est un ange, un diamant brut, toutes ces mains, ces oreilles et ces bouches, d'Irun à Ixelles, pour faire passer, écouter, pour comprendre-et pour joyeusement ne pas comprendre. Tu as ici les continents, les mers, les dieux 
et les forces contraires, tu as ici les empêchements, les flots vagues flux toutes les grimaces et tu as une personne, pas un flot de personnes, une personne, une perle précieuse, comme on dit à Irun, suivie d'ici à là, suivie sauvée par un groupe de personnes qui ne se connaissent pas mais suivent sauvent ensemble, sauvent une personne, ouvrent les portes, rusent avec les portes, tu sais, ces petites cales qu'on peut coincer dedans pour ouvrir quand on ne peut plus ouvrir. Toutes, qui suivent sauvent ensemble, un, une, chacun, chacune.

Dans le village que je connais, quand les jeunes sont venus en répit, comme on disait alors, le cafetier du village était contre. On raconte qu'il tenait au début des propos dignes de ceux de Marcelin de Barogne. Le cafetier du village que je connais n'a jamais refusé de servir qui que ce soit mais il constatait et faisait constater qu'il n'était pas prêt à s'enrichir, avec ces gars-là. Les copains et les copines, tout le monde, disait-il, étaient allé.e.s les aider. On n'imaginait pas du tout capable le cafetier de ce village de formuler les choses très ordurières que disent Dédé, Émile et les copains, dans Tout homme est une nuit.

Ni s'emporter comme ils le font.

T'emporter seul, pendant que les copains vont aider?

On aurait dit qu'il en avait une fierté par procuration, de ses copains et copines qui étaient allé.e.s aider. Peut-être n'osait-il pas, devant nous, formuler autre chose mais ce n'était pas si mal qu'il n'ose pas. Si souvent on se met en tête de ressembler aux choses qu'on dit, comme si on pouvait s'y résumer.

Le cafetier, dans le village que je connais, disait que tout le monde avait aidé et que bah, à part la pêche, bien sûr (ils attrapent les truites quand c'est pas le moment), ils sont pas si différents, au fond. 
À quoi ça tient?

À très peu, aux copains et copines qui ont aidé, à ces filles qui posent la question après coup et qui ont l'air de trouver génial ce qui s'est passé au village.

Et les actes tiennent un peu aux discours qu'on tient.

À Barogne, les propos dégueulasses sont suivis d'une chasse à l'homme.

Mais ni dans ses discours ni dans ses actes, on n'est tout entier.

Le cafetier de Barogne, Marcelin, n'est pas que ce qu'il a l'air d'être.

Il n'est pas que les discours de haine qu'il tient.

Il n'est pas que ses actes.

Il est aussi le père d'Augustin.

Cette jeune fille de quinze ans s'est mise, au village, à pleurer à chaudes larmes devant les hôtes du Soudan et d'Erythrée.

Elle les voit, elle pleure.

Son père dit qu'elle a peur.

Elle n'a jamais vu de noirs, alors elle a peur.

Elle-même dit qu'elle a peur, elle dit que c'est la raison de ses larmes.

Le mot peur en enferme d'autres.

Du trop, du trop grand, le monde, un monde?

Un jeune homme que je connais, plein d'arguments et de joie, accueille ces jeunes de son âge. Il écoute les longues routes, les parcours tortueux, les aberrations. Après quelques jours il découvre sur son corps des manifestations cutanées inhabituelles, une sorte d'eczéma.

C'est rien, dit le médecin-en effet le symptôme cutané guérit dans la nuit.

Le jeune homme dit : je ne suis plus le même. 
Je change, tu vois, je change de peau.

Il y a le désir de n'être pas tout à fait le même, on peut ne pas le savoir et moins on le sait, plus le désir est accompagné de peurs, de symptômes.

Marcelin et Dédé n'ont pas envie de changer de peau.

Certainement, Lydie Salvayre le suggère, ils ont trop peur.

Au village, chez nous, dans plein de villages, dans de plus en plus de villes et villages, des hommes et des femmes, des familles entières, sont accueillies dans d'autres familles.

Aux réunions, les personnes viennent avec leurs questions et leurs peurs. Mais quelles sont leurs peurs ? Légalité ou pas. Mon métier ou pas. Ma maison ou pas. Plus d'une semaine, je ne peux pas. Or, je ne mettrai personne dehors. Que faire donc à la fin de la semaine? Moi, je dirais un mois. Que faire après un mois ? C'était une question morale. Si je ne fais pas c'est par peur de ne pas faire assez. Ce qui en retenait quelques-uns, c'était la question morale qu'il y avait tant à faire, qu'on devait le faire jusqu'au bout. C'était un devoir moral, humain. Les devoirs moraux, humains, ne s'arrêtent pas en chemin.

Le lien humain, ce truc qui s'est brisé dans le roman de Lydie Salvayre, ce truc brisé qui fait que Jacques préférerait quitter le village pour vivre dans une cabane, à la Thoreau.

Les jours de réunion, on laisse vivre des espaces doucement flous. On se dépatouille bien. Augustin se dépatouille bien dans le roman : il parle. Il passe par-dessus l'inhumanité, en parlant. 
Quand Martine a appelé avant la fin de la première semaine : le garçon est adorable. Mais il va mal, il a passé toute sa vie dans des camps, il ne dort pas, du coup je ne dors pas. Il ne comprend aucune langue, ni l'anglais ni l'arabe. Il fait ses prières. C'est un homme. Je suis une femme. Vite, trouver un relai, pour que Martine dans cette histoire ne se sente jamais plus fragile qu'elle ne peut le supporter, qu'elle ne se sente jamais fragile comme Dédé, Émile ou Marcelin.

Dire : on fait avec et à partir de notre impuissance, notre immense impuissance.

Notre impuissance à consoler, notre impuissance à nous consoler nous-mêmes.

Dire : il faut supporter notre impuissance. Faire quand même. C'est ainsi qu'on ne deviendra pas ce qu'on peut toujours devenir, l'Histoire le sait-les personnages de Tout homme est une nuit aussi. 